\title{
PENGARUH LATIHAN BOUNCE BALL 2 VS 2 DAN 3 VS 3 TERHADAP KELINCAHAN ATLET TAEKWONDO
}

\author{
Setiyawan \\ Jurusan Pendidikan Jasmani Kesehatan dan Rekreasi, Universitas PGRI Semarang, Semarang, Indonesia \\ *setiyawan@upgris.ac.id
}

(Received: July 2018 / Revised: August 2018 / Accepted: September 2018)

ABSTRAK : Penelitian yang dilakukan mempunyai tujuan untuk mengetahui pengaruh latihan bounce ball 2 vs 2 dan 3 vs 3 terhadap kelincahan atlet taekwondo. Penelitian ini menggunakan model penelitian eksperimen semu two groups pretest-posttest design. Kelompok eksperimen merupakan kelompok yang latihan dengan metode bounce ball 2 vs 2 dan 3 vs 3. Populasi yang digunakan adalah seluruh atlet taekwondo Universitas PGRI Semarang yang berjumlah 38 atlet. Teknik pengambilan sampel menggunakan purposive sampling, sampel yang memenuhi syarat berjumlah 20 atlet. Pembagian kelompok menggunakan match subject ordinal pairing (MSOP). Instrumen yang digunakan adalah hexagonal agility test dengan nilai reliabilitas tes 0.938. Analisis data menggunakan uji t. Hasil penelitian menunjukkan ada pengaruh peningkatan kelincahan pada kelompok 2 vs 2 dengan dengan peningkatan 4,48\%, dan ada pengaruh peningkatan kelincahan kelompok 3 vs 3 dengan peningkatan $2.68 \%$.

KATA KUNCI : Bounce ball, Kelincahan, Taekwondo.

ABSTRACTS : Research conducted has a purpose to determine the effect of ball bounce training vs. 2 and 3 vs. 3 against the agility of taekwondo athletes. This research uses two groups pretest-posttest design. The experimental group is a group that exercises by bounce ball 2 vs 2 and 3 vs. 3. The population used is all athletes taekwondo University PGRI Semarang, amounting to 38 athletes. Sampling technique using purposive sampling, eligible sample amounted to 20 athletes. Division of groups using match subject ordinal pairing (MSOP). Instrument used is hexagonal agility test with test reliability value 0.938. Data analysis using $t$ test. The test results showed that there was an effect of increasing agility in group 2 vs 2 with 4.48\% increase, and there was an effect of increasing group agility 3 vs 3 with 2.68\% increase.

KEYWORD :

Bounce ball, Agility, Taekwondo.

\section{PENDAHULUAN}

Kualitas sumber daya manusia suatu negara bisa dilihat dari kualitas prestasi olahraga negara tersebut (Setiyawan, 2017: 1). Dalam pembinaan prestasi olahraga tujuan utama yang akan dicapai bisa merupakan tujuan jangka pendek maupun tujuan jangka panjang. Salah satu cabang beladiri yang populer dan dipertandingkan secara resmi sampai event olimpiade adalah cabang olahraga taekwondo. Cabang olahraga taekwondo adalah cabang olahraga beladiri yang dominan menggunakan teknik kaki untuk menyerang. Cabang olahraga taekwondo sendiri berasal dari negara Korea. Dalam sistem pertandingan taekwondo pemenang ditentukan oleh perolehan poin yang didapat. Aturan poin yaitu 2 poin untuk tendangan ke badan dengan teknik lurus, 3 poin untuk tendangan ke arah kepala, 4 poin untuk teknik tendangan dengan teknik berputar kea rah badan, dan 4 poin untuk tendangan berputar kearah kepala (WTF: 2017, 18). Salah satu faktor yang mempengaruhi prestasi atlet taekwondo adalah faktor fisik, pada cabang taekwondo kualitas fisik yang diperlukan meliputi: kekuatan, kelincahan, kecepatan, daya tahan, kelentukan, fleksibilitas dan power, sedangkan Irianto (2009: 15) berpendapat bahwa unsur-unsur gerak fisik umum meliputi: kekuatan, kecepatan, daya tahan, dan kelentukan. Unsur-unsur gerak fisik khusus meliputi: stamina, daya ledak, reaksi, koordinasi, ketepatan, dan keseimbangan. 
Kualitas fisik ini dapat dikembangkan melalui latihan secara kontinyu. Rendahnya kualitas fisik mempengaruhi keberhasilan suatu prestasi olahraga. Untuk itu dalam taekwondo ada beberapa komponen fisik yang harus dikembangkan. Salah satu komponen biomotor spesifik di taekwondo adalah komponen kelincahan. Menurut Sukadiyanto (2010: 136) kelincahan atau agility merupakan kemampuan seseorang untuk bisa merubah arah dengan cepat. Dari hasil pengamatan yang ada masih belum banyaknya model variasi latihan kelincahan yang mampu membuat atlet senang untuk mengikuti program latihan tersebut. Rata-rata model latihan kelincahan yang ada merupakan model latihan konvensional yang sudah ada. Maka diperlukan model latihan yang menyenangkan dan bisa meningkatkan kelincahan atlet taekwondo. Salah satu pengembangan latihan kelincahan adalah dengan metode latihan bounce ball, dimana latihan ini adalah metode latihan dengan pendekatan permainan dan memanfaatkan bola.

\section{METODE PENELITIAN}

Metode yang digunakan dalam penelitian ini adalah metode eksperimen semu two groups pretest-posttest design. Dimana metode ini adalah metode penelitian yang memberikan perlakuan kepada sampel atau orang coba. Penelitian ini dilakukan 12 kali pertemuan dengan populasi sebanyak 38 atlet taekwondo Universitas PGRI Semarang. Penarikan sampel menggunakan teknik purposive sampling. Dimana teknik ini menggunakan syarat untuk menentukan sampel. Dalam penelitian ini syarat yang digunakan adalah: 1) atlet putra, 2) Sudah latihan taekwondo minimal 9 bulan, dan 3) Merupakan atlet taekwondo cabang kyourugi/tanding. Dari teknik ini maka didapat 20 sampel. Sampel yang sudah terpilih kemudian di tes dengan menggunakan instrument kelincahan hexagonal agility test dengan nilai validitas 0.896 dan reliabilitas 0.938 , setelah itu sampel dibagi menjadi dua dengan teknik MSOP (match subject ordinal pairing).
Teknik MSOP dapat digambarkan dengan gambar 1 sebagai berikut.

Gambar 1. Match Subject Ordinal Pairing

\begin{tabular}{ccc}
\hline A & B \\
\hline $1 \rightarrow$ & 2 \\
4 & $\downarrow$ \\
$5 \rightarrow$ & \\
$8 \rightarrow 6$ \\
$9 \rightarrow$ & $\leftarrow 7$ \\
\hline
\end{tabular}

Dari hasil MSOP didapat 2 kelompok, yaitu kelompok A untuk perlakuan dengan latihan bounce ball 2 vs 2 dan kelompok B dengan perlakuan latihan bounce ball 3 vs 3 . Teknik analisis data yang digunakan adalah uji normalitas, uji homogenitas dan uji hipotesis dengan uji-t. Pengolahan data menggunakan program SPSS 20 for windows.

\section{HASIL}

Hasil penelitian yang sudah dilakukan diperoleh data normalitas pada tabel 1 sebagai berikut:

Tabel 1. Normalitas Data

\begin{tabular}{lcc}
\hline Kelompok & $\begin{array}{c}\text { Kolmogorov- } \\
\text { Smirnov }\end{array}$ & Keterangan \\
\hline Pre test $2 \times 2$ & 0.922 & Normal \\
\hline Post test $2 \times 2$ & 0.962 & Normal \\
\hline Pre test $3 \times 3$ & 0.948 & Normal \\
\hline Post test $3 \times 3$ & 0.839 & Normal \\
\hline
\end{tabular}

Dari tabel di atas diketahui normalitas data kelompok pre test 2 vs 2 sebesar 0.922, data post test kelompok 3 vs 3 sebesar 0.962 , data pre test 3 vs 30.948 dan data normalitas post test 3 vs 3 0.839. Dari data tersebut dapat disimpulkan seluruh data normal.

Selanjutnya dilakukan penghitungan homogenitas. Data penghitungan homogenitas bisa dilihat pada tabel 2 sebagai berikut: 
Tabel 2. Homogenitas Data

\begin{tabular}{cccccc}
\hline Kel. & $\begin{array}{c}\text { Levene } \\
\text { statistic }\end{array}$ & $\begin{array}{c}\mathbf{d f} \\
\mathbf{1}\end{array}$ & $\begin{array}{c}\mathbf{d f} \\
\mathbf{2}\end{array}$ & Sig. & $\begin{array}{c}\text { Keteranga } \\
\mathbf{n}\end{array}$ \\
\hline $2 \times 2$ & 0.01 & 1 & 18 & 0.974 & Homogen \\
\hline $3 \times 3$ & 0.538 & 1 & 18 & 0.956 & Homogen \\
\hline
\end{tabular}

Dari tabel homogenitas tersebut didapat data 2 vs 2 dengan nilai 0.974 dan kelompok 3 vs 3 dengan nilai 0.956 dari hasil tersebut maka dapat simpulkan data dari kedua kelompok homogeny.

Kemudian dilakukan uji beda hasil analisis pre test dan post test kelompok A yaitu kelompok latihan bounce ball 2 vs 2 dapat dilihat pada tabel 3 sebagai berikut:

Tabel 3. Deskripsi Statistik Kelompok 2 vs 2

\begin{tabular}{lrr}
\hline Statistik & \multicolumn{1}{l}{ Pretest } & \multicolumn{1}{c}{ Postest } \\
\hline $\mathrm{N}$ & 10 & 10 \\
\hline Mean & 16.8440 & 16.0890 \\
\hline Std. Deviation & 0.52314 & 0.61269 \\
\hline Maximum & 17.66 & 17.06 \\
\hline Minimum & 15.98 & 15.12
\end{tabular}

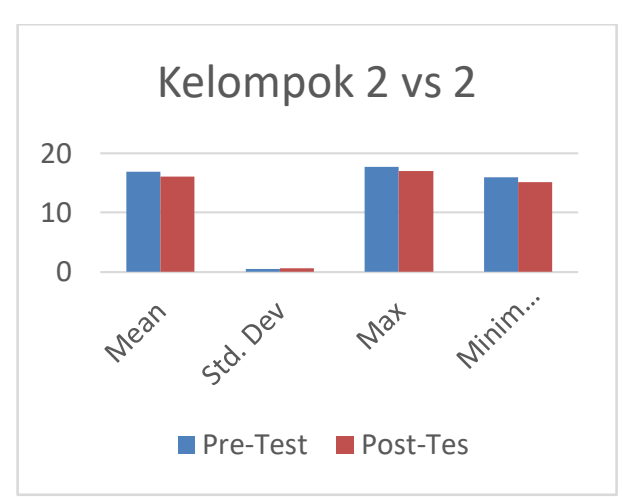

Grafik 1. Hasil Deskripsi Kelompok 2 vs 2

Dari hasil di atas ada perbedaan mean pre tes dan post test kelompok perlakukan A, dimana data mean pre test awal 16.8440 dan post test mean kelompok A 16.0890 . Nilai maksimum pre test kelompok A 17.66 dan pada post test nilai maksimum sebesar 17.06. Ada perbedaan deskripsi data minimum pre test kelompok A yaitu 15.98 dan post test sebesar 15.12. Kemudian hasil analisis statistik pre test dan post test kelompok B yaitu kelompok latihan bounce ball 3 vs 3 dapat dilihat pada tabel 4 sebagai berikut:

Tabel 4. Deskripsi Statistik Kelompok 3 vs 3

\begin{tabular}{lrr}
\hline Statistik & \multicolumn{1}{c}{ Pretest } & \multicolumn{1}{c}{ Postest } \\
\hline $\mathrm{N}$ & 10 & 10 \\
\hline Mean & 16.8550 & 16.4030 \\
\hline Std. Deviation & 0.33570 & 0.33570 \\
\hline Maximum & 17.26 & 17.00 \\
\hline Minimum & 16.35 & 16.00 \\
\hline
\end{tabular}

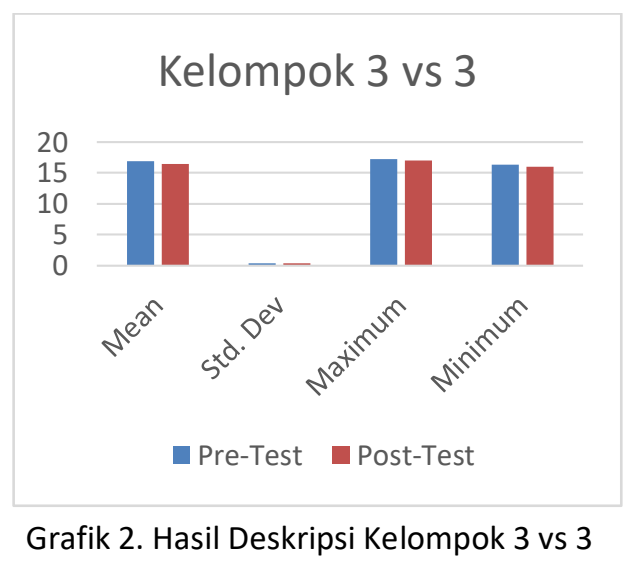

Dari hasil di atas ada perbedaan mean pre tes dan post test kelompok perlakukan $\mathrm{B}$, dimana data mean pre test awal 16.8550 dan post test mean kelompok B 16.4030. Nilai maksimum pre test kelompok B 17.26 dan pada post test nilai maksimum sebesar 17.00. Ada perbedaan deskripsi data minimum pre test kelompok $B$ yaitu 16.35 dan post test sebesar 16.00 .

Perbandingan perbedaan peningkatan perlakuan dapat dilihat pada grafik berikut:

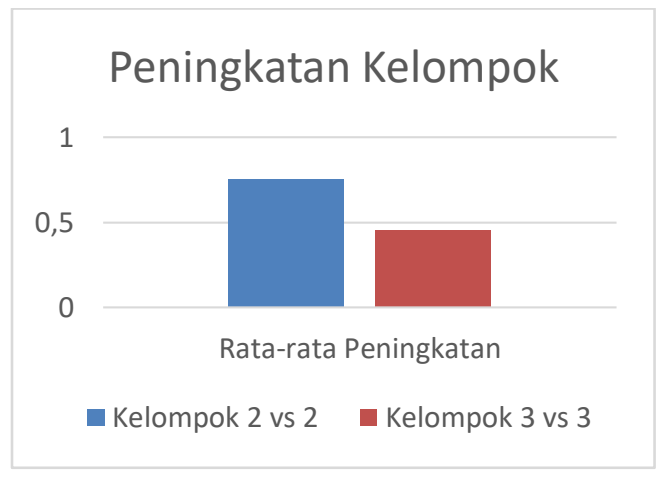

Grafik 3. Perbandingan Peningkatan Kelompok 
Selanjutnya dilakukan uji-t untuk menguji hipotesis. Uji T dapat dilihat pada tabel berikut:

Tabel 5. Uji T

\begin{tabular}{lcccc}
\hline Kelompok & T Hitung & T Tabel & df & Sig \\
\hline Kelompok 2 vs & 5.287 & 2.23 & 9 & 0.0 \\
2 & & & & 01 \\
\hline Kelompok 3 vs & 7.522 & 2.23 & 9 & 0.0 \\
3 & & & & 00 \\
\hline
\end{tabular}

Dari tabel di atas didapat bahwa baik kelompok $A$ dan kelompok $B$ t hitung lebih besar dari $\mathrm{t}$ tabel maka hipotesis yang berbunyi ada pengaruh latihan bounce ball 2 vs 2 dan 3 vs 3 terhadap kelincahan diterima.

\section{PEMBAHASAN}

Dari hasil penelitian yang dilakukan metode latihan bounce ball 2 vs 2 memiliki prosentase peningkatan kelincahan yang lebih tinggi daripada 3 vs 3 . Kelompok 2 vs 2 dengan tingkat peningkatan $4.48 \%$ dan kelompok 3 vs 3 dengan peningkatan $2.68 \%$. Hal ini disebabkan karena metode 2 vs 2 memaksa subyek untuk bergerak lebih cepat dan lincah agar tidak dengan mudah terkena bola yang dilempar oleh lawan. Pergerakan merubah arah dengan cepat inilah yang menyebabkan meningkatnya kelincahan pada subyek coba. Hal ini senada dengan penelitian yang dilakukan Lehnert (2013) dimana agility merupakan kemampuan merubah arah dengan cepat yang membutuhkan kontraksi otot dengan cepat dan dapat dirangsang dengan stimulus berupa bentuk latihan yang menyebabkan perubahan arah secara tiba-tiba dan mendadak.

\section{SIMPULAN DAN REKOMENDASI}

Dari hasil penelitian dapat disimpulkan model latihan bounce ball 2 vs 2 dan 3 vs 3 dapat meningkatkan kelincahan. Hasil pengujian menunjukkan ada pengaruh peningkatan kelincahan pada kelompok 2 vs 2 dengan thitung $5.287>2.23$ (t tabel) dengan peningkatan 4,48\%, dan ada pengaruh peningkatan kelincahan kelompok 3 vs 3 dengan $t$ hitung $7.522>2.23$ (t tabel) dengan peningkatan $2.68 \%$. Model ini bisa digunakan untuk pelatih klub sebagai inovasi dalam latihan kelincahan.

\section{UCAPAN TERIMAKASIH}

Ucapan terimakasih penulis tujukan kepada UKM Taekwondo Universitas PGRI Semarang dan Program Studi PJKR atas dukungan yang diberikan.

\section{REFERENSI}

Beekhuizen, K. S., Davis, M. D., Kolber, M. J., \& Cheng, M. S. S. (2009). Test-retest reliability and minimal detectable change of the hexagon agility test. The Journal of Strength \& Conditioning Research, 23(7), 2167-2171.

Bompa, Tudor. O. (2000). Theory and Methodology for Young Champions. Champaign II: Human Kinetics.

Cholid Narbuko. (2007). Metodologi Penelitian. Jakarta: Bumi Aksara.

Departemen Pendidikan Nasional. (2000). "Pedoman dan Modul Pelatihan Kesehatan Olahraga Bagi Pelatih Olahragawan Pelajar". Jakarta : Pusat Pengembangan Kualitas Jasmani.

Devi Tirtawirya. (2005). "Metode Melatih Teknik dan Taktik Taekwondo". FIK. UNY.

Harsono. (1988). Coaching dan aspek-aspek psikologis dalam coaching.Jakarta: Depdikbud.

Kim, H. B., Stebbins, C. L., Chai, J. H., \& Song, J. K. (2011). Taekwondo training and fitness in female adolescents. Journal of sports sciences, 29(2), 133-138.

Lehnert, M., Hůlka, K., Malý, T., Fohler, J., \& Zahálka, F. (2013). The effects of a 6 week plyometric training programme on explosive strength and agility in professional basketball players. Acta Gymnica, 43(4), 7-15.

Miranda, D. L., Hsu, W. H., Gravelle, D. C., Petersen, K., Ryzman, R., Niemi, J., \& Lesniewski-Laas, N. (2016). Sensory 
enhancing insoles improve athletic performance during a hexagonal agility task. Journal of biomechanics, 49(7), 10581063.

Raya, M. A., Gailey, R. S., Gaunaurd, I. A., Jayne, D. M., Campbell, S. M., Gagne, E., ... \& Tucker, C. (2013). Comparison of three agility tests with male servicemembers: Edgren Side Step Test, T-Test, and Illinois Agility Test. Journal of Rehabilitation Research \& Development, 50(7).

Sambamurthy, V., Bharadwaj, A., \& Grover, V. (2003). Shaping agility through digital options: Reconceptualizing the role of information technology in contemporary firms. MIS quarterly, 237-263.

Setiyawan, S. (2017). KEPRIBADIAN ATLET DAN NON ATLET. Jendela Olahraga, 2(1).

SETIYAWAN, S. (2017). Visi Pendidikan Jasmani dan Olahraga. JURNAL ILMIAH PENJAS, 3(1).

Sheppard, J. M., \& Young, W. B. (2006). Agility literature review: Classifications, training and testing. Journal of sports sciences, 24(9), 919932.

Sugiyono. (2007). "Metode Penelitian Kuantitatif Kualitatif Dan R \& D". Bandung: Alfabeta.

Suharsimi Arikunto. (2002). "Prosedur Prosedur Penelitian: Suatu Pendekatan Praktek". Edisi Revisi VII. Jakarta: Rieneka Cipta.

Sukadiyanto. (2010). "Pengantar Teori dan Metodologi Melatih Fisik". Yogyakarta: FIK.UNY.

The World Taekwondo Federation. (2004). "Competition Rules \& interpretation". Jakarta: komisi Perwasitan PBTI.

The World Taekwondo Federation. (2007). "Poomsae Competition Rules \& Interpretation". Jakarta : komisi Perwasitan PBTI.

V. Yoyok Suryadi. (2002). "Taekwondo Poomse Taegeuk". Jakarta : PT Gramedia Pustaka Utama 